$\gamma$-globulin. When more fully characterised there is hope that these factors may be useful as adjuvants to conventional immunosuppressive regimens and may find regular application in the protocol for the treatment of severe rejection rather than being used as a "last-ditch" measure.

This work was supported by National Heart and Lung Institute Research grants HL 08696 and HL 13108, and US Public Health Service Research grant RR 70.

1 Occhino, J C, et al, fournal of Immunology, 1973, 110, 685.

2 Coulson, A S, et al, Transplantation, 1974, 18, 409.

3 Coulson, A S, and Inman, D R, Guy's Hospital Reports, 1971, 120, 89.

4 Cooperband, S R, et al, fournal of Immunology, 1972, 109, 154.

5 Buckley, R H, et al, fournal of Immunology, 1972, 108, 34.

Department of Cardiovascular Surgery, Stanford University Medical Centre, Stanford, California, USA

ALAN S COULSON, MB, PHD, chief resident

VIRGINIA H ZEITMAN, BS, ASCP, research technician

EDWARD B STINSON, MD, associate professor

RANDALL B GRIEPP, MD, assistant professor

CHARLES P BIEBER, MD, research associate

EUGENE DONG jun, $M D$, associate professor

NORMAN E SHUMWAY, MD, FACS, chairman of department

\section{Lupus glomerulitis and renal vein thrombosis}

Hamilton and Tumulty described a patient with lupus nephritis and thrombosis of the renal veins and of the inferior vena cava. ${ }^{1}$ We report here a case of systemic lupus erythematosus with lupus glomerulitis, unilateral renal vein thrombosis, and the nephrotic syndrome.

\section{Case report}

A 24-year-old woman was admitted to hospital in January 1975 because of fever, myalgia, and arthralgia of two years' duration. She had frontal alopecia, splenomegaly, hemolytic anaemia, leucopenia, positive LE cell test, and a $\mathrm{C} 3$ of $0.56 \mathrm{~g} / \mathrm{l}$ (normal $0.9-1 \cdot 8$ ). SLE was diagnosed. The urine contained protein, occasional red and white blood cells (high power field), and a few granular casts. Serum creatinine was $62 \mu \mathrm{mol} / 1(0.7 \mathrm{mg} / 100 \mathrm{ml})$, albumin $24 \mathrm{~g} / 1$, and cholesterol $3.6 \mathrm{mmol} / 1(140 \mathrm{mg} / 100 \mathrm{ml})$. Creatinine clearance. was $84 \mathrm{ml} / \mathrm{min}$ and 24-hour urinary protein excretion was $5.2 \mathrm{~g}$. An intravenous pyelogram showed nothing abnormal. Renal biopsy showed slight mesangial hypercellularity and focal glomerulitis with one haematoxylin body. She was discharged on $20 \mathrm{mg}$ of prednisone and $6 \mathrm{mg}$ of chlorambucil daily.

By April, despite restoring the serological abnormalities to normal (negative ANF anti-DNA tests and a C3 of $0.92 \mathrm{~g} / 1$ ), she had oedema up to the thighs. Prednisone was increased to $60 \mathrm{mg} /$ day and she was readmitted. Her serum albumin was $13 \mathrm{~g} / 1$, cholesterol $9.2 \mathrm{mmol} / 1(355 \mathrm{mg} / 100 \mathrm{ml})$, and the urinary protein loss $18.6 \mathrm{~g} / 24 \mathrm{~h}$. The platelet count and coagulogram were normal and no cryoglobulins were found. Renal venography showed a nonocclusive thrombus on the right side (fig). Diuretics were given along with heparin. By May the oedema had gone and the serum albumin had risen to $21 \mathrm{~g} / \mathrm{l}$. Protein loss was $9 \mathrm{~g} / 24 \mathrm{~h}$. When last seen in July 1975 she was symptom free, with a serum albumin of $38 \mathrm{~g} / 1$ and normal serology and creatinine clearance, but she was excreting protein $5 \mathrm{~g} / 24 \mathrm{~h}$. She was receiving warfarin, dipyridamole, prednisone, and chlorambucil.

\section{Discussion}

The normal anti-DNA titre and the hypocomplementenaemia at the onset of massive proteinuria in this patient suggests a renal disease other than lupus. ${ }^{2}$ Unilateral renal vein thrombosis may be associated with the nephrotic syndrome, ${ }^{3}$ in some cases of which a hypercoagulable state has been identified, ${ }^{4}$ but the normal coagulogram was against this in our case. There was no evidence of thrombotic thrombocytopenic purpura, intravascular coagulopathy,

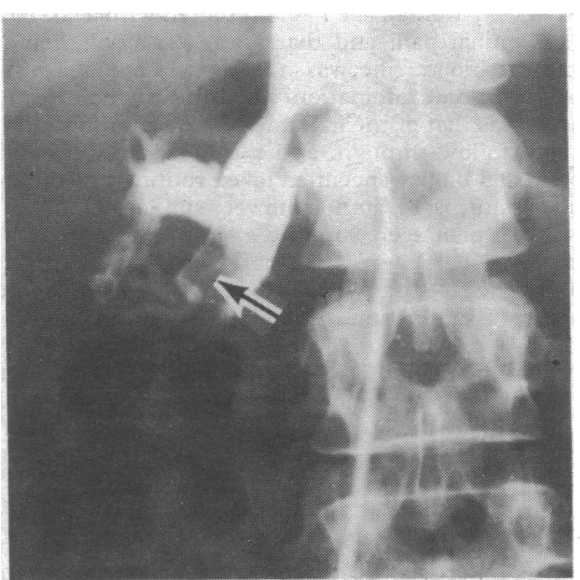

Non-occlusive thrombus in major inferior renal vein (arrow) on right side.

Raynaud's phenomenon, macroglobulinaemia, or cryoglobulinaemiaconditions that are associated with SLE and could result in transient or permanent vascular occlusion.

The most common glomerular lesion associated with renal vein thrombosis is membranous glomerulopathy. ${ }^{5}$ The association in our case, however, is more difficult to explain. Minimal glomerular disease, such as glomerulitis, in SLE rarely causes massive proteinuria. Factors predisposing to deep venous thrombosis, such as oral contraception, pregnancy, and pelvic or extremity phlebitis, were absent. We must assume that she had either a lupus glomerulitis which caused the nephrotic syndrome and that the latter led to renal vein thrombosis, or that she had lupus glomerulitis and a concommittent, but unrelated, renal vein thrombosis. Whichever is correct, a full renal investigation, including venography or delayed arteriography, seems appropriate whenever the renal manifestations of lupus are greater than the renal lesion or the extrarenal and serological activity of the disease seem to warrant, since prompt diagnosis and early anticoagulation treatment of renal vein thrombosis reduce further renal damage.

1 Hamilton, C, and Tumulty, P, Fournal of the American Medical Association, 1968, 206, 2315.

2 Townes, A, fohns Hopkins Medical fournal, 1967, 120, 337.

3 Moore, H L, et al, Pediatrics, 1972, 50, 598.

4 Kendall, A G, Lohmann, R C, and Dossetor, J B, Archives of Internal Medicine, 1970, 127, 1021.

5 Johannessen, J V, Archives of Pathology, 1974, 97, 277.

Department of Internal Medicine, American University of Beirut Hospital, Beirut, Lebanon

GEORGE S BRIDI, MD, clinical assistant professor, nephrology section RIDA A FRAYHA, MD, assistant professor rheumatology section

\section{Serum ferritin levels in acute hepatocellular damage from paracetamol overdosage}

Serum ferritin levels accurately reflect the iron storage status of the individual in health and also in certain diseases. ${ }^{1}$ In liver disease, however, levels are elevated, reflecting hepatocellular damage, and Prieto $e t a l^{2}$ found a close linear correlation between the serum ferritin-transaminase ratio and liver iron concentration. We have measured serum ferritin levels in 25 patients admitted for acute paracetamol overdosage and examined their correlation with both transaminase levels and the degree of hepatocellular damage ascertained from liver biopsy. 


\section{Methods and results}

All patients had ingested paracetamol within the preceding 18 hours. Daily routine liver function tests and serum ferritins were performed and liver biopsy was obtained on the fourth or fifth day or when the prothrombin ratio was normal if that was later. One pathologist assessed biopsies blind and graded them as showing mild, moderate, or severe changes as described elsewhere. ${ }^{3}$ The patients were placed into three groups according to conventional liver function tests. Group 1 (eight females and one male) no liver damage. Serum aspartate aminotransferase (SGOT) within normal range (4-20 IU). Liver biopsy grading showed eight with mild and one with moderate damage. Group 2 (five females and three males): moderate damage. SGOT rose but did not exceed 400 IU. Biopsy gradings showed one with mild and seven with moderate damage. Group 3 (eight females): severe damage. SGOT rose higher than 400 IU. Biopsy grading showed eight with severe damage. The groups did not differ with regard to time between ingestion of paracetamol and admission to hospital. Serum ferritin was measured by immunoradiometric assay as described by Addison et al, and values above $6000 \mu \mathrm{g} / 1$ were not measured quantitatively. Reference values were established in healthy laboratory and medical staff. In 12 males the range was $32-240 \mu \mathrm{g} / 1$ (mean $102 \mu \mathrm{g} / \mathrm{l}$ ). In 16 females the range was $17-158 \mu \mathrm{g} / \mathrm{l}$ (mean $53 \mu \mathrm{g} / \mathrm{l}$ ).

Serum ferritin levels rose steadily and reached a peak on the third or fourth day in all groups (see table). The differences between the groups on the third day were statistically significant (groups $1-2 \mathrm{P}<0.025$; groups $2-3 \mathrm{P}<0.001)$

Mean serum ferritin levels $(\mu g / l)$ in patients studied $( \pm S E$ of mean). Transaminase values are shown in parentheses $(I U)$

\begin{tabular}{l|c|c|c|c}
\hline & Day 1 & Day 2 & Day 3 & Day 4 \\
\hline Group 1 & $92 \pm 24$ & $138 \pm 49$ & $213 \pm 72$ & $171 \pm 44$ \\
Group 2 & $(14 \pm 1)$ & $(12 \pm 1)$ & $(11 \pm 1)$ & $(12 \pm 1)$ \\
Group 3 & $339 \pm 109$ & $569 \pm 212$ & $779 \pm 213$ & $881 \pm 361$ \\
& $(33 \pm 12)$ & $(50 \pm 14)$ & $(81 \pm 33)$ & $(41 \pm 10)$ \\
& $(637 \pm 95$ & $1652 \pm 491$ & $5168 \pm 623$ & $4013 \pm 1229$ \\
& & $(869 \pm 447)$ & $(693 \pm 150)$ & $(860 \pm 314)$ \\
\hline
\end{tabular}

Group 1. By the third day only three patients had attained levels outside our reference values but eight had levels that had significantly increased from the initial value (mean percentage increase $166 \pm 63 \mathrm{SE}$ of mean).

Group 2. By the third day six patients had elevated levels and the mean percentage increase was $359 \pm 196$.

Group 3. All patients had vastly increased ferritin by the third day, six exceeding $6000 \mu \mathrm{g} / \mathrm{l}$, and the lowest value being $1070 \mu \mathrm{g} / \mathrm{l}$. The mean percentage increase was $1745 \pm 483$.

The serum transaminase levels $s_{\text {also }}$ showed a marked difference on the third day between the groups (groups $1-2$. $P<0.05$; groups $2-3 \mathbf{P}<0.005$ ) but levels peaked inconsistently between patients. In five patients the serum ferritin rose above normal before the SGOT, and in a further nine the rise occurred on the same day. Only two patients had elevated SGOT levels and ferritins which remained within our reference values. There was no overall correlation between ferritin and transaminase levels on the third day $(r=0.369 ; P>0.10)$, but when the ferritin changes were expressed as a percentage of the initial values, a definite correlation emerged $(r=0.491$; $\mathbf{P}<0.05$ ).

The results of the liver biopsy gradings show excellent agreement with the groupings, the main feature being that all patients in group 1 had mild pathological changes despite normal transaminases, and levels exceeding 400 IU always indicated severe liver damage.

\section{Discussion}

Liver damage following paracetamol overdose is practically inevitable though conventional liver function tests may be normal. We have shown that serum ferritin levels in acute hepatocellular damage, when the onset of the insult was known, correlate closely with pathological changes and are more sensitive than transaminase estimations. Since serum ferritin in health has been shown to have neither diurnal variation nor any marked daily fluctuation, ${ }^{5}$ any increase would suggest liver damage. We suggest that further studies should be undertaken into serum ferritin levels in patients at risk from hepatocellular damage-for example, drug trials-and that such research may help to elucidate controversial topics such as halothane hepatitis.

We thank Professor A L Latner and the Department of Clinical Biochemistry for transaminase estimations and Dr A J Watson and Dr M Lesna for pathological help. We acknowledge grants from the Medical Research Council and from the Scientific and Research Committee, University Hospitals of Newcastle upon Tyne.

1 Jacobs, A, and Worwood, M, New England fournal of Medicine, 1975, 292, 951.
2 Prieto, J, Barry, M, and Sherlock, Sheila, Gastroenterology, 1975, 68, 525. 3 James, O F W, et al, Lancet, 1975, 2, 579.

4 Addison, G M, et al, fournal of Clinical Pathology, 1972, 25, 326.

5 Siimes, M A, Addiego, J E, and Daliman, P R, Blood, 1974, 43, 581.

Gastroenterology Group, Department of Medicine, Royal Victoria Infirmary, Newcastle upon Tyne NE1 4LP

E J EASTHAM, MB, MRCP, research associate

J I BELL, technician

A P DOUGLAS, MB, MRCP, consultant gastroenterologist

\section{Hypoglycaemia in children undergoing adenotonsillectomy}

Preoperative hypoglycaemia in children is well recognised. Bevan and Burn $^{1}$ found that $30 \%$ of children starved for operation had blood glucose concentrations of less than $3.33 \mathrm{mmol} / 1(60 \mathrm{mg} / 100 \mathrm{ml})$ at induction of anaesthesia.

\section{Case report}

A previously healthy 5-year-old girl was admitted for routine adenotonsillectomy. After surgery there was slight haemorrhage from the adenoid bed, which was recuretted uneventfully in theatre. Subsequently, in spite of no further blood loss, no hypotension, and a steady pulse rate, she became progressively paler with cold extremities and did not respond to painful stimuli. Blood was transfused, and after $30 \mathrm{ml}$ she had a generalised convulsion. At this point no glucose was found in the blood. She responded to intravenous dextrose treatment, and two days later was discharged in good health.

After this case, 32 consecutive children admitted for tonsillectomy or adenoidectomy, or both, aged from 3 to 11 were studied. Their blood glucose levels were estimated immediately on return from theatre by low-reading Dextrostix (see table), interpolating when necessary. A reading between $2.50 \mathrm{mmol} / 1(45 \mathrm{mg} / 100 \mathrm{ml})$ and $5.00 \mathrm{mmol} / 1(90 \mathrm{mg} / 100 \mathrm{ml})$ was taken as $3.61 \mathrm{mmol} / 1(65 \mathrm{mg} / 100 \mathrm{ml})$. This technique gives an excellent correlation with true blood glucose levels abtained by quantitative methods. ${ }^{2}$

Blood glucose values in 32 children after adenotonsillectomy

\begin{tabular}{|c|c|c|c|c|c|}
\hline $\begin{array}{l}\text { Blood glucose (Dextrostix) (mmol/l) } \\
\text { No of children }\end{array}$ & $\because$. & $1 \cdot 39$ & $\begin{array}{l}2 \cdot 50 \\
12\end{array}$ & $\begin{array}{c}3.61 \\
3\end{array}$ & $\begin{array}{c}5 \cdot 00 \\
13\end{array}$ \\
\hline
\end{tabular}

Conversion: SI to traditional units-Glucose: $1 \mathrm{mmol} / 1 \approx 18 \mathrm{mg} / 100 \mathrm{ml}$.

By conventional criteria $(<2.78 \mathrm{mmol} / 1 \quad(50 \mathrm{mg} / 100 \mathrm{ml}))$ half these patients were hypoglycaemic. Even by Cornblath and Schwartz's ${ }^{3}$ criteria $(<2.22 \mathrm{mmol} / 1(40 \mathrm{mg} / 100 \mathrm{ml}))$, four patients $(12.5 \%)$ were hypoglycaemic. Age did not appear to influence greatly the incidence of hypoglycaemia.

\section{Discussion}

Hitherto, common practice has been to give children undergoing adenotonsillectomy fluids only after bedtime on the evening before operation and nothing by mouth after 8 am for an afternoon operating session or after midnight for a morning session. Thus periods of starvation of six to 20 hours occur. By custom, patients have been starved before general anaesthesia to reduce the risk of vomiting and aspiration of gastric contents. Recently Thomas showed that this was no more likely to occur if children drank milk up to four hours before operation than if they were starved for eight hours. ${ }^{4}$ In Thomas's study no hypoglycaemia occurred in the first group. In the second group $15 \%$ had blood glucose levels below $2 \cdot 22 \mathrm{mmol} / 1(40 \mathrm{mg} / 100 \mathrm{ml})$.

There is no constant relation between the level of blood glucose and the occurrence of hypoglycaemic symptoms. Thus fits, with consequent brain damage, spasticity, and mental deficiency, may occur without warning in an asymptomatic patient. In animal studies levels of blood glucose below $1.11 \mathrm{mmol} / 1(20 \mathrm{mg} / 100 \mathrm{ml})$ for two hours cause ischaemic cell change affecting neurones in the neocortex, 